\title{
REHABILITATION PROGRAM IN CLINICAL CASE OF POLY TRAUMA
}

\author{
G. Mratzkova, R. Paskaleva, A. Gyonkova \\ Department "Medical Rehabilitation and Occupational Therapy, Physical Medicine and Sport", \\ Medical Faculty, Trakia University, Stara Zagora
}

\begin{abstract}
Fractures in the cervical spine are among the most common injuries of locomotor apparatus and nervous system in patients with poly trauma. These are severe pathology injuries and primarily affect people of working age. In spinal reconstructive interventions the recovery period is considerably shortened,there is no need for prolonged immobilization in halo traction and extended wear of immobilization collar in the absence of spinal injury.

The purpose of this paper is to present a comprehensive rehabilitation program for patients with severe trauma of cervical spine, shoulder girdle and chest.

Material and Methods. A comprehensive rehabilitation program is composed and implemented on 41 year old patient suffered an accident. There are radiographic scan and Traffic Police evidence of fracture of the second cervical vertebra fracture, mnogo fragment fracture of right humeral head and dislocation of the right humerus, fracture of the left collarbone in the distal third and $12^{\text {th }}$ rib fracture on the left. No evidence of abdominal trauma.

Results and discussion. The rehabilitation is consistent with the objective condition of the patient at each stage for optimum recovery of functional activity and training in daily life activity. Applied are kinesitherapeutical methods and preformed physical factors aimed at reducing pain syndrome, hypotrophy of the affected muscles, limited range of motion and prevention of late posttraumatic complications.

Findings and conclusion. As a result of the surgery, comprehensive and timely rehabilitation the following results were achieved: maximum restore of the volume of movement of the affected joints of the right upper limb and cervical spine; improved was the muscular strength of flexor muscles and extensors in the elbow and shoulder joints; right upper limb was fully involved in daily life activity. Recommended is continuing of treatment at home or in specialized sanatorium rehabilitation centers.
\end{abstract}

Key words: clinical case poly trauma, recovery, complex rehabilitation.

\section{INTRODUCTION}

Fractures of cervical spine are among the most common injuries of the musculoskeletal system and the nervous system. They are characterized by severe pathology and affect mainly people of working age $[9,10]$. In spinal reconstructive interventions the recovery period is significantly shortened, eliminating the need for prolonged halo traction immobilization and prolonged wear of immobilization collar in the absence of spinal damage [10].

The aim of this paper is to present the clinical case of a patient with data for combined fracture in the upper cervical spine, right shoulder bone, in the distal contralateral clavicle and a fracture of left rib.

\section{MATERIAL AND METHODS}

This is a case of 41 year old patient suffered an accident, having a roentgenographic evidence and data from traffic police for fracture of the second cervical vertebra, mono- fragment fracture the head of the right shoulder bone and dislocation of the right shoulder bone, a fracture of the left clavicle in the distal third and fractured left twelfth rib. No evidence of abdominal trauma.

An two-stage surgery is performed. On the second day after the injury is done occipito spino surgery to $\mathrm{C} 0-\mathrm{C} 1-\mathrm{C} 2-\mathrm{C} 3$ through titanium plate fixed to squama occipitalis and six polyaxial titanium screws transmasa lateralis to $\mathrm{C} 1, \mathrm{C} 2$ and $\mathrm{C} 3$. No evidence of damage to the nerve structures. 

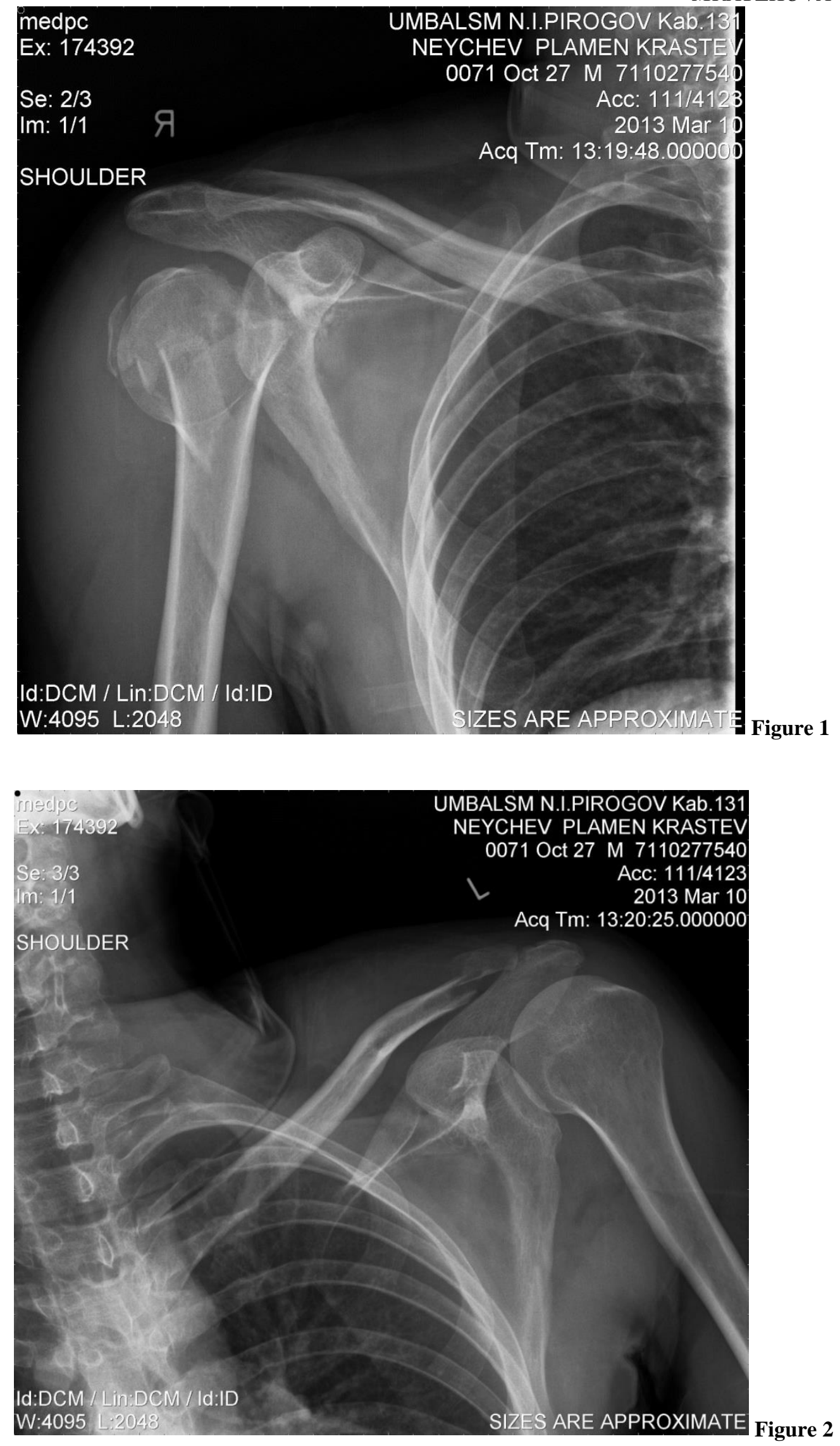

Figure 1 and 2. Roentgenography of right and left shoulder joint

On the tenth day after the injury an operational repositioning and metal osteosynthesis of the humerus with the LCP placae have been done. The postoperative period flowed without complications- without sensory and circulatory disorders in the operated limb.
The patient is directed for rehabilitation two months after surgery, conducted in stages in inpatient and outpatient conditions. 
MRATZKOVA G., et al.

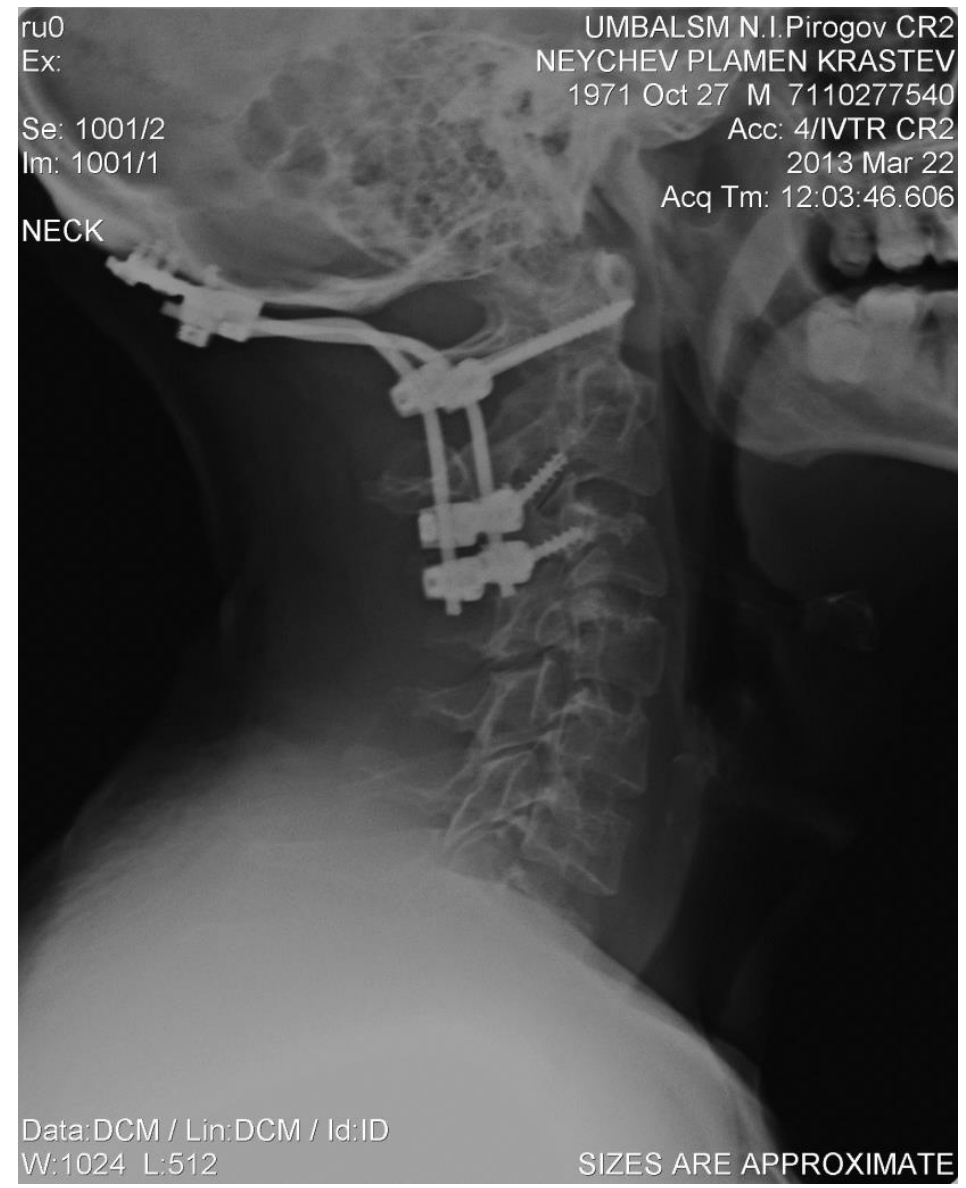

Figure 3. Cervical roentgenography after occipito spino surgery to $\mathrm{C} 0-\mathrm{C} 1-\mathrm{C} 2-\mathrm{C} 3$

Stage 1: rehabilitation activities conducted in an outpatient conditions.

Reported is a pain and limited mobility in the right shoulder joint and cervical spine, and difficulty in performing activities of daily life. The patient is in a good general condition. No evidence of cardiovascular and pulmonary pathology. There is a spontaneous pain, growing when attempting to move the shoulder joint, largely limited to impossible active and passive movements, expressed hypotrophy of the muscles in the neck-shoulder-area. Limited mobility in the cervical spine. The patient is wears an orthotic collar. No evidence of neurological deficit.

The rehabilitation program was consistent with the general condition of the patient and the established rehabilitation potential based on functional tests, MMT and angle measurements.

Purpose of the rehabilitation program: Functional recovery of the affected motor segments.

Tasks: Overcoming post-traumatic pain syndrome; increase the volume of movement in the lower cervical spine and right shoulder joint, overcome muscle imbalances, reduce shoulder muscle hypotrophy for abductors and external rotators; prevention of subsequent complications and post-traumatic dystrophic syndrome, shoulder-arm syndrome.

Means: Active kinesitherapy- respiratory gymnastics; isometric exercises for $\mathrm{m}$. delatoideus dextra; active isotonic exercises for elbow joint until full flexion and extension, pronation and supination in 90 degree flexion of the forearm, wrist and distal sections of the hand; lightweight fly free movements for flexion, extension, abduction and adduction and circumduction in the right shoulder joint with minimal muscle effort and mainly waving. Isotonic gravitational free exercises for abduction in right shoulder joint; contralateral workout for the uninjured upper limb; Kinesitherapy for the cervical spine is conducted after removing the orthotic collar. Passive methods: therapeutic massage for the lower neck and chest muscles. Active isotonic exercises- free position for flexion, extension and lateral tilt of the lower cervical area $[1,2$, $3,4]$.

Stage 2: 10 days course of rehabilitation is conducted in "Physical Medicine and Rehabilitation" ward at the Hospital "Prof. Dr. Stoyan Kirkovich" - Stara Zagora. The patient is in a good general condition and reported moderate pain and restriction in movement of 
MRATZKOVA G., et al.

the right shoulder joint and neck. No evidence of associated pathology of the cardiovascular system and respiratory system. There are limited active and passive movements of the right shoulder joint, there is hypotrophy of muscles in the shoulder area. There is limited mobility in the cervical spine.

Composed is a rehabilitation program based on data from the general and local status and the stated rehabilitation potential after the conducted functional tests, MMT and angle measurements.

Purpose of the program rehabilitation: Optimal functional recovery of the affected motor segments.

Tasks: Recovery of the volume of movement in the cervical spine and right shoulder joint, overcoming hypotrophy for abductors and external rotators of the shoulder joint; restoration of the scapula-humeral rhythm, prevention of alternative movements, reducing the effects of post-traumatic pain syndrome and muscle imbalance, preventing late posttraumatic complications, gradually involving the limb in activities of daily live.

Means: Active kinesitherapy - respiratory gymnastics; isometric exercises for $\mathrm{m}$. deltoideus dextra; analytical exercises for right shoulder joint and paravertebral muscles; active isotonic exercises for the elbow joint for flexion and extension, pronation and supination in 90 degree flexion of the forearm, wrist and distal sections of the hand; free movements for flexion, extension abduction and adduction, and circumduction in the right shoulder joint. Isotonic gravitational free exercises for abduction in right shoulder joint; exercises in suspension; contralateral workout for the uninjured upper limb; exercises in closed kinetic chain for right upper limb. Kinesiherapy for cervical spine. Isometric exercises for the paraspinal muscles; active isotonic exercises for free position for flexion, extension and lateral tilt of the lower cervical spine $[1,5,6,7]$.

\section{Preformed physical factors:}

Electrostimulation with rectangular pulses $10 \mathrm{~ms}, 50 \mathrm{~Hz}$, separately for pars anterior, pars lateralis et pars posterior $\mathrm{m}$. delatoideus dextra; 10 procedures;

Low-frequency pulsed magnetic field to the right shoulder joint and along the right upper limb $14000 \mathrm{~A} / \mathrm{m}, 10 \mathrm{~Hz}, 0,2 \mathrm{~s} 15 \mathrm{~min} 10$ procedures.

\section{RESULTS AND DISCUSSION}

After the first stage the outpatient treatment ends with significantly improved active movements of the affected upper limb (Table. 1 ), as the movements in the sagittal and frontal plane of the right shoulder joint are done by eliminated gravity. Movements are with reduced pain and improved muscle tone of the upper limbs. The limb is gradually included into the activities of everyday life. the patient is directed for hospitalization with stationary rehabilitation.

Table 1. Functional tests

\begin{tabular}{|l|l|l|}
\hline & $\begin{array}{l}\text { Angle } \\
\text { measurements }\end{array}$ & MMT \\
\hline $\begin{array}{l}\text { Shoulder joint when } \\
\text { hospitalized }\end{array}$ & $\begin{array}{l}\mathrm{S} 0^{\circ}-0^{\circ}-0^{\circ} \\
\text { F } 0^{\circ}-0^{\circ}-0^{\circ}\end{array}$ & $\begin{array}{l}\text { extension pars posterior m. delatoideus 1 } \\
\text { flexion pars anterior m. delatoideus 1 } \\
\text { abduction pars lateralis m. delatoideus 1 } \\
\text { adduction 1 }\end{array}$ \\
\hline Shoulder joint on $10^{\text {th }}$ day & $\begin{array}{l}\mathrm{S} 15^{\circ}-0^{\circ}-45^{\circ} \\
\text { F } 35^{\circ}-0^{\circ}-0^{\circ}\end{array}$ & $\begin{array}{l}\text { extension 2 } \\
\text { flexion 2 } \\
\text { abduction 2 } \\
\text { adduction 1 }\end{array}$ \\
\hline
\end{tabular}

Table 2. Functional tests

\begin{tabular}{|l|l|l|}
\hline & $\begin{array}{l}\text { Angle } \\
\text { measurements }\end{array}$ & MMT \\
\hline $\begin{array}{l}\text { Shoulder joint when } \\
\text { hospitalized }\end{array}$ & $\begin{array}{l}\text { S } 15^{\circ}-0^{\circ}-45^{\circ} \\
\text { F } 35^{\circ}-0^{\circ}-0^{\circ}\end{array}$ & $\begin{array}{l}\text { extension pars posterior m. delatoideus 2 } \\
\text { flexion pars anterior m. delatoideus 2 } \\
\text { abduction pars lateralis m. delatoideus 2 }\end{array}$ \\
\hline $\begin{array}{l}\text { Shoulder joint when } \\
\text { released from hospital }\end{array}$ & $\begin{array}{l}\text { S } 15^{\circ}-0^{\circ}-95^{\circ} \\
\text { F } 50^{\circ}-0^{\circ}-0^{\circ}\end{array}$ & $\begin{array}{l}\text { extension 4 } \\
\text { flexion 4 } \\
\text { abduction 3 } \\
\text { adduction 2 }\end{array}$ \\
\hline
\end{tabular}


After the second stage of rehabilitation of the patient (Table. 2) the motor activity of the right upper limb and the entire cervical part of the spine is significantly recovered and the patient is released from the hospital having reduced pain and improved mobility of the right shoulder joint and the lower cervical section. Instructions are given for proper hygiene, diet and exercise regime at home, and for continuing the active rehabilitation. An occupational therapy and art therapy are recommended in the rehabilitation program.

\section{FINDINGS AND CONCLUSIONS}

As a result of traffic accidents often more than one anatomical part is affected and the general condition of the patient is deteriorated. Modern surgery enables the rapid recovery of the patient and the early initiation of rehabilitation activities. After restoration of the anatomic integrity of the injured body organ, the adequate and timely implemented physical medicine is essential for the functional recovery of the injured patients.

A result of the surgery, the comprehensive and timely rehabilitation the following results were achieved:

- The affected joints of the right upper limb and cervical spine recovered to the maximum amount of movement;

- The muscle strength of the flexor and extensors muscles in elbow and shoulder joints had been improved;

- The active movements of these muscles were performed in a full volume against moderate resistance;

- The right upper limb was fully involved in the activities of daily living;

- The participation of the patient was complete in carrying out activities to maintain personal hygiene and daily living activities.

It is recommended that the treatment should continue at home or in specialized sanatorium rehabilitation centers.

\section{REFERENCES}

MRATZKOVA G., et al.

1. Vacheva D. Study of the effect of the use of occupational therapeutic activities as a part of the comprehensive rehabilitation of patients with distal radius fracture, Abstract of thesis for awarding educational and scientific degree of Doctor, 2010, Pleven, p.59

2. Karaneshev G., Theory and methods of medical gymnastics, Medicine and Sports, 1991.

3. Kostadinov D., L. Nikolova, Bankov St., Slunchev P., The physical factors in the complex treatment and rehabilitation of some common diseases, Sports and Medicine, 1980.

4. Kostadinov, D., Todorov L., Peneva J., Panteva T., Manual for medical gymnastics, Medicine and Sports, 1985.

5. Riazkova M. Kirova I., Physical therapy general and special part, Sofia 2002.

6. Slunchev P., Bonev L., Bankov St., Manual for physical therapy, Medicine and Sports, 1986.

7. Tsonchev V. Devetakova B., Medical Rehabilitation, Medicine and Sports

8. Blackmore CC, Emerson SS, Mann FA, Koepsell TD. Cervical spine imaging in patients with trauma: determination of fracture risk to optimize use. Radiology. 1999, 211 (3): 759-65.

9. Barros Filho TEP, Oliveira RP, Barros EK, Von Uhlendorff EF, Iutaka AS, Cristante $\mathrm{AF}$, et al. Ferimento por projétil de arma de fogo na coluna vertebral: estudo epidemiológico [Gunshot wounds of the spine: epidemiological study] Coluna / Columna. 2002, 1 (2): 83-7.

10.Jefferson G. Fracture of the atlas vertebra. Report of four cases and a review of those previously recorded. British Journal of Surgery.1919, 7 (27): 407-22. 